\title{
Chronic pain in adolescents is associated with suicidal thoughts and behaviors
}

\author{
Miranda A.L. van Tilburg, PhD ${ }^{1}$, Naomi J. Spence, $\mathrm{PhD}^{2}$, William E. Whitehead, PhD ${ }^{1}$, \\ Shrikant Bangdiwala, $\mathbf{P h D}^{1}$, and David B. Goldston, $\mathbf{P h D}^{3}$ \\ ${ }^{1}$ University of North Carolina, Center for Functional GI and Motility Disorders, Chapel Hill, NC \\ 2 Lehman College, City University of New York, Bronx, NY \\ ${ }^{3}$ Duke University School of Medicine, Durham, NC
}

\section{Abstract}

Adults who suffer from chronic pain are at increased risk for suicide ideation and attempts, but it is not clear whether adolescents with chronic pain are similarly at increased risk. This study investigates whether chronic pain is associated with an increase in suicidal ideation/attempts independent of depression in a population sample of adolescents.

We analyzed data from the National Longitudinal Study of Adolescent Health, a longitudinal study of a nationally representative sample of adolescents in the United States $(\mathrm{N}=9,970)$. Most chronic pain was related to suicide ideation/attempt both in the last year (OR's 1.3-2.1) and during the subsequent year (OR's 1.2-1.8). After controlling for depressive symptoms, headaches $(\mathrm{OR}=1.3$ last year, $\mathrm{OR}=1.2$ subsequent year) and muscle aches $(\mathrm{OR}=1.3$ last year) remained associated with suicide ideation but not suicide attempt.

These findings show that chronic pain in adolescence is a risk factor for suicide ideation; this effect is partly but not fully explained by depression. Youth with co-morbid depression and chronic pain are at increased risk of thinking about and attempting suicide. Clinicians should be alert to suicide ideation/attempt and co-morbid depression in this at-risk population.

\section{Index words}

Pain; Suicide; Epidemiology; Adolescents

\section{Introduction}

Chronic pain affects up to a quarter of adolescents $32,20,41,43,12$ and can have detrimental impacts on the adolescent's functioning and quality of life $29,50,5324,6$. Despite these poor outcomes, in the majority of patients, no organic cause of the pain can be found. This absence of findings reassures the clinician that no underlying pathology will affect the

\footnotetext{
(C) 2011 The American Pain Society. Published by Elsevier Inc. All rights reserved.

Please send all correspondence to: Miranda van Tilburg, PhD, University of North Carolina, Center for Functional GI and Motility Disorders, CB 7080, Chapel Hill NC 27516, Phone 919843 0688, tilburg@ med.unc.edu.

The authors have no conflicts of interest related to this manuscript

Publisher's Disclaimer: This is a PDF file of an unedited manuscript that has been accepted for publication. As a service to our customers we are providing this early version of the manuscript. The manuscript will undergo copyediting, typesetting, and review of the resulting proof before it is published in its final citable form. Please note that during the production process errors may be discovered which could affect the content, and all legal disclaimers that apply to the journal pertain.
} 
morbidity or mortality of the patient. However, results from several studies in adults have shown that in some cases, the suffering due to pain can be so severe that patients contemplate suicide. ${ }^{51,27,5,9,22,25,37,46,47,48,28,55}$ The link between pain and suicide is especially relevant to adolescents as this is an age period at which suicidal thoughts and behaviors peak; in $200913.8 \%$ of youths in the US had seriously considered suicide and $6.3 \%$ attempted suicide ${ }^{7}$.

To date, only one study investigated the link between suicide ideation or attempts and pain in adolescence. Among Norwegian adolescent psychiatric outpatients, a significant relationship was observed between suicide attempts and frequent pain, indicating that similar to adults, pain may be associated with suicidality in adolescents ${ }^{38}$. Given the fact that these data were collected from a psychiatric sample, it is not clear whether the findings can be easily generalized to a larger group of adolescents with chronic pain.

The link between suicidal thoughts/behaviors and chronic pain could be explained by shared risk factors. The most obvious shared risk factor is comorbid depression. Depression is one of the most important risk factors for suicide $49,23,13$ and depression is increased in chronic pain patients ${ }^{16,14}$. In addition, pain and depression share similar physiological pathways: neurological changes in the amygdala and hippocampus are observed in both and antidepressants are effective in treating both ${ }^{26,52}$. These data suggest that in chronic pain patients, comorbid depression may increase the risk for suicide thoughts/behaviors.

Thus, even though a small literature is available suggesting that suicide ideation/attempt and pain are related in adults, studies in youth are needed. We aim to confirm the finding, derived primarily from clinical samples in adults, that: (1) chronic pain is associated with an increase in suicidal ideation and suicidal attempts in a population sample of adolescents, and extend this finding by examining (2) the degree to which the association between pain and suicidal behaviors is attributable to depression, given that depression is a major risk factor for both pain and suicide behaviors in adolescents. ${ }^{49,23,1316,14,54}$ In complementary approaches, we examined the relationship between pain both with suicidal thoughts/behavior over the last year, and with suicidal thoughts/behavior over the subsequent year.

\section{Methods}

We applied secondary data analyses to The National Longitudinal Study of Adolescent Health (Add Health). Add Health is a longitudinal study of a nationally representative sample of adolescents in grades 7-12 in the United States (details are given below).

\section{Design and sampling}

Eighty high schools and 52 middle schools from the US were selected with unequal probability of selection. Incorporating systematic sampling methods and implicit stratification into the Add Health study design ensured this sample is representative of US schools with respect to region of country, urbanicity, school size, school type, and ethnicity. Data during adolescence were collected in two waves; third and fourth wave data were collected during adulthood and do not contain pain data so these waves will not be described here:

1. The first wave, conducted from September 1994 through December 1995, included in-home, in-school, parent and school administrator questionnaires. Data were obtained on demographic variables, depression, chronic pain and suicide ideation/ attempt at this wave.

2. The second wave, conducted from April 1996 through August 1996, consists of inhome interviews and school administrator interviews. The interviews were 
scheduled 1 year after the Wave 1 in-home interview and more than $90 \%$ of students were interviewed within 3 months of their scheduled interview time. Only students who were still attending high school were included. Data were obtained on depression, chronic pain and suicide ideation/attempt at this wave. More detailed design information can be found on http://www.cpc.unc.edu/projects/addhealth/design.

\section{Measures}

(1) Demographic variables-Gender was reported by the adolescent. Age was determined by subtracting the date of birth from the date of the interview. Race/ethnicity was reported by the adolescent and categorized as: White non-Hispanic, Black nonHispanic, Hispanic, Multiracial, and Other. Parental education level was based on parental report of highest educational level, when available; otherwise, this information was obtained during the adolescent interview. Parent education was categorized as: less than high school, high school graduate, some college, college graduate, and higher. Demographic data were collected in Wave I.

(2) Pain-The following questions were answered on a 5-point scale (never, just a few times, about once a week, almost every day, every day): "Please tell me how often have you had each of the following conditions during the past 12 months": (a) headache, (b) stomachache or upset stomach, (c) aches, pains or soreness in your muscles or joints". These are the most common forms of chronic pain in children and adolescents ${ }^{44,32,41,12}$. Pain that persists for more than 3 months has been commonly described as chronic in population studies ${ }^{32,41,44}$. Those adolescents who reported pain 'never' or 'just a few times" in the past year clearly would not be considered to suffer from chronic pain. Thus we included adolescents in the chronic pain category if they reported experiencing pain once a week or more in the past 12 months. Similar definitions of chronic pain in this study population have been used in previous publications. ${ }^{56,40,39}$ Data regarding pain were collected in Wave I and II.

(3) Depression-Depression was measured by a 16 -item version of the Centers of Epidemiologic Studies Depression Scale (CES-D) ${ }^{42,36}$. The CES-D is a widely used selfreported depression scale and has excellent psychometric properties. It is valid for use in both junior and senior high school student populations $s^{35}$ and has been found to be related to suicide ideation in the current sample ${ }^{15}$. Depressive symptoms were measured for the past week. Data regarding depression were collected in Wave I and II.

(4) Suicide Ideation and Attempt-Suicide ideation and attempt were measured by two items: "During the past 12 months did you ever seriously think about committing suicide?" and for those who answered positively: "During the past 12 months, how many times did you actually attempt suicide?" Answers are dichotomized into "never" and "one or more times". These items are consistent with the standardized nomenclature for suicidology proposed by O' Carroll and colleagues ${ }^{30}$ in which suicide ideation is defined as "any selfreported thoughts about engaging in suicide-related behavior" and suicide attempt is "a potentially self-injurious behavior with a nonfatal outcome for which there is evidence that the person intended at some level to kill him/herself." Data regarding suicidal ideation/ attempt were collected in Wave I and II.

\section{Data analyses}

To avoid overlap with studies in adults, we limited analyses of the database to those subjects below the age of 18 at Wave I (2.5\% of the sample was excluded). Probability sample weights were used in all analyses to produce national sample population estimates. 
Univariate cross-sectional analyses were performed to describe the sample and compare adolescents who reported any frequently recurring pain to adolescents who did not report frequent pain with respect to depression and suicide ideation and attempt at each wave of data.

The design of the dataset posed unique challenges and opportunities. Data on pain, suicide ideation/attempt, and depression from the same wave were used to investigate whether pain and depression were associated with suicide ideation and suicide attempts during the last year. However, since both pain and suicide ideation/attempt were measured over the past year it was equally possible for pain to precede or follow suicidal thoughts/attempts. In addition, because the measure of depression only reflected depressive symptomatology during the last week, it was possible that depression may not have been present before the onset of either pain or suicidality. To make sure that both pain and depression preceded suicidality, we conducted a second set of analyses in which pain and depression at Wave I were examined as predictors of subsequent suicide ideation and suicide attempts in Wave II. These analyses have the advantage of establishing precedence between purported risk factors and outcomes but may arguably not include the most important covariates of suicidal thoughts and behavior: current depression and pain. Considering pros and cons for each type of analysis, both were conducted as complementary approaches.

In the first set of logistic regression analyses, the presence of suicide ideation and attempts at Wave I were dependent variables while pain and depression at Wave I were independent variables. Age and gender main effects as well as age/gender by pain interactions were tested. Since the interactions were non-significant, interaction terms were not retained in the regression models. However, as is conventional, age and gender were entered first into the regression analyses as covariates. Similar cross-sectional analyses were run for Wave II data.

In the second set of logistic regression analyses, pain and depression assessed at Wave I were independent variables examined as predictors of reports of suicide ideation and attempts one year later (Wave II), while controlling for age and gender. Since previous suicide ideation/attempt is the single best predictor of future suicide ideation attempt, we also conducted the above analyses in a more restrictive sample of youth who did not report previous suicide ideation/attempt at Wave 1.

Commonly reported test of goodness of fit for logistic regression analyses (e.g., HosmerLemeshow test ${ }^{17}$ ) are not appropriate for use in complex sample survey data. The HosmerLemeshow test for example assumes that data come from a simple random sample. However the Add health data come from a complex sample requiring the use of sample weights to account for differential probabilities of selection. Ignoring sample weighting can lead to inflated type I errors and thus invalid statistical tests Therefore an F-adjusted mean residual test is reported as developed by Archer and Lemeshow ${ }^{4}$. Small p-values indicate a lack of fit for the model. All data were analyzed using STATA 11 (StataCorp LP) using the svy module to support statistical analysis of complex survey data.

\section{Results}

\section{Description of the sample}

Demographic variables and rates of pain, suicide ideation and attempts at Wave I and II are presented in Table 1. In consideration of the low base rate of suicide attempts, we determined whether the sample had adequate power to test associations with this outcome. Sample sizes required to test the hypothesis that the population multiple correlation equals zero with a power of .80 and alpha $=.05$ were determined according to calculations as 
outlined by Cohen ${ }^{8}$. For 4 independent variables (pain, depression, gender and age), a sample size of 84 is needed to detect medium effect sizes $\left(f^{2}=.15\right.$; which is typical for behavioral research). The lowest number of subjects endorsing suicide attempt (in Wave II) was $\mathrm{N}=341$. Thus, we have sufficient power to test the association between suicide ideation/ attempt and pain.

\section{Hypothesis 1: Chronic pain is associated with an increase in suicidal ideation and attempts in adolescents}

Is chronic pain associated with suicide ideation and attempt in the last year?

-Analyses of Wave I and II data revealed that suicide ideation and attempt were increased in those who report chronic pain versus those who did not report pain (See Table 2). These findings were apparent for all forms of chronic pain except for muscle ache. Muscle aches were associated with suicide ideation but showed only a trend for an association with suicide attempt.

Although significant main effects were noted for gender $(\mathrm{OR}=1.7,95 \% \mathrm{CI}=1.5-2.1$ for suicide ideation Wave I; OR=1.6; 95\% CI=1.2-2.0 for suicide ideation Wave II; OR=2.7, $95 \% \mathrm{CI}=1.9-4.0$ for suicide attempt wave $\mathrm{I})$ and age $(\mathrm{OR}=1.1,95 \% \mathrm{CI}=1.06-1.2$ for suicide ideation Wave I), there were no interactions between pain and gender or age. This suggests that age and gender do not affect the relation between suicide and pain. Data described in Table 2 have been adjusted for age and gender effects.

Does pain predict suicide ideation and attempt 1 year later?-As can be seen in Table 3, all forms of chronic pain in Wave I predicted subsequent suicide ideation and attempts with the exception of headaches, which were only related to suicide attempts at the trend level. Gender $(\mathrm{OR}=2.8,95 \% \mathrm{CI}=2.1-3.8$ for suicide attempt; and $\mathrm{OR}=1.9,95 \%$ $\mathrm{CI}=1.6-2.2$ for suicide ideation) but not age was related to suicidality. However, the interaction of pain by gender was not significant suggesting that gender does not affect the relation between suicide and pain.

\section{Hypothesis 2: The association between chronic pain and suicide ideation/attempt is independent of depression}

Adolescents who reported chronic pain at Wave I were more depressed ( $M=10.9 ; \mathrm{sd}=5.8)$ than adolescents who did not report chronic pain $(\mathrm{M}=8.3, \mathrm{sd}=7.0 ; \mathrm{p}<.0001)$. Similar results were found for wave II $(\mathrm{M}=10.4, \mathrm{sd}=5.9$ versus $\mathrm{M}=8.5, \mathrm{sd}=7.0 ; \mathrm{p}<.0001)$.

Is pain associated with suicide ideation/attempt in the last year independent of depression?-When controlling for depression, both chronic headaches and chronic muscle aches remained associated with suicide ideation in the last year in Wave I (see Table 2). Both headaches and stomachaches were associated with suicide ideation in the last year in Wave II after controlling for depression. In contrast, when controlling for depression, chronic pain was no longer significantly associated with suicide attempts in Wave I, but was associated with headaches in Wave II.

Does pain predict suicide ideation/attempt 1 year later while controlling for depression?-While controlling for depression, only chronic headaches remained a significant predictor of suicide ideation 1 year later (see Table 3). Chronic pain was no longer associated with suicide attempts after controlling for depression. 


\section{Discussion}

In a large nationally representative sample of adolescents, we found that self-reported chronic pain was associated with increased risk of suicide ideation and attempts. These findings are similar to observations among adults $48,22,37,5$. This association did not vary as a function of age and gender, indicating that suicidality is increased in both boys and girls of all ages who suffer from chronic pain. We also observed that pain was associated with an increase in suicidal thoughts and behaviors 1 year later. Thus, pain is associated with both increased likelihood of suicidal thoughts and attempts in the last year, as well as increased suicidal thoughts and behavior in the subsequent year. More studies are needed to determine if chronic pain plays a causative role in the development of suicide ideation and thoughts.

Pain and suicidal thoughts or ideation may not be directly linked. Underlying factors could explain the co-occurrence of both. One such a factor is depression. Depression is an important risk factor for suicidality, and co-morbid depression is common in pain patients. We found that chronic pain, and specifically chronic headache, was associated with suicide ideation after controlling for depression. This is in accordance with previous studies which have found that chronic pain in adults is associated with increased suicide ideation/attempt independently of depression ${ }^{25,28}$. In contrast, suicide attempts among youth with chronic pain were largely associated with the presence of depression. Thus, youth with co-morbid pain and depression maybe at heightened risk for suicide attempt. Even though we did not find an independent effect of pain on suicide attempts in this large sample, clinicians working with individual cases should be open to the possibility that youth with pain but no depression may still confer a risk for suicide attempt. Previous studies have found that although depression is a main risk factor for suicide, not all suicide attempts occur in the presence of depression ${ }^{2}$. Indeed, all patients reporting thoughts of wanting to kill themselves should be closely monitored by their physicians. However, the current findings do imply that the presence of depression among individuals with chronic pain is significantly related to increased risk of suicide attempts. Clinicians should be especially vigilant in monitoring risk among young patients with chronic pain and depression, and in helping these young patients receive appropriate treatment for both their pain and their depression.

The present study does not allow us to investigate why chronic pain and suicidality are related. A recent review by Tang and Crane ${ }^{51}$ identified 8 risk factors for suicidality in chronic pain divided into general risk factors (family history of suicide, previous suicide attempt, being female and co-morbid depression) and pain-specific factors (pain location, intensity, duration and co-morbid insomnia). In our current study, we didn't find an effect of general risk factors such as gender and age. Furthermore, as discussed above, the relationship of headache pain to future suicide ideation and both headache and stomachache pain to previous year's suicide ideation and attempts was largely independent of depression. It is possible that pain-specific factors, such as duration/intensity and control over the pain, may explain why some young pain patients are at increased risk for suicidality. Moreover, pain and suicide may share similar biological pathways that can explain their association. For example, serotonin has been implicated in both pain and suicide ideation/attempt but so far the overlap has not been studied ${ }^{10,31}$.

To our knowledge, this is the first study to observe an association between chronic pain and suicide ideations/attempts in a population-based sample of adolescents. This is an important age period because there is an increased risk of suicidality; suicide is one of the major causes of death in adolescence and for every death, there are 100-200 attempts leaving many adolescents prone to self-inflicted injury ${ }^{11}$. Rates of suicide attempt in our study and others range form 4-6\% in this age group and suicide ideation is 2 to 3 times more 
common ${ }^{7}$. Increased ability to recognize those adolescents who are at risk for suicide and offering appropriate care can make an important difference in the lives of many.

The strength of the current study is the large nationally representative sample of youth in the United States and the longitudinal design allowing us to look at the association of pain with suicide ideation/attempt over time. However, it also has some weaknesses which should be acknowledged. First, all data are based on self-reports, which may be subject to issues of recall. Memory bias may have varied across the variables of interest as pain and suicide ideation/attempt were based on a 12-month recall and depressive symptoms were measured in the past week. Moreover, current depression could increase recall of pain and/or suicide ideation/attempt in the past year. Second, despite the longitudinal design of the study, no inference can be made about causality: even if pain is associated with suicidality 1 year later, other factors than pain may explain this link. Third, since this is an existing dataset, the timing of assessing chronic pain, depression and suicide ideation/attempt may not be optimal to understand the temporal relation to each other. And last, the dataset is limited by the amount of medical information related to pain. The subjects in the study reported that they have suffered from at least weekly episodes of pain in the past year, but the dataset does not contain information about the causes of pain or its severity. For most chronic pain, no illness or injury is found upon medical examination that would explain the pain symptoms ${ }^{3,45}$. In this context, it appears that most of the chronic pain reported in this study would be consistent with the definition of chronic pain as set forth by the International Association for the Study of Pain, namely: "pain that persists beyond the usual course of an acute illness or injury or beyond what is the usual time for recovery"1,21. In the case of abdominal pain, non-painful conditions may also have been included. Subjects were asked about both "stomachaches" and "upset stomach". The last may have included stomach discomfort such as bloating, nausea or early satiety. These symptoms may or may not be associated with pain and thus a minority of patients may have been included who had non-painful stomach discomfort. Considering that non-painful conditions are included in our abdominal pain group, the association between abdominal pain and suicide ideation/attempt is probably under-estimated in this study. To supplement the findings from this population study, data from clinical samples are needed, in which cause and treatment of pain and temporal ordering of pain relative to depression and suicide ideation/attempt are available,.

In sum, $25-50 \%$ of youth in our study and other population studies suffer from chronic pain ${ }^{41,32}$. Chronic pain in youth is associated with significant psychiatric comorbidity, reduced quality of life, restrictions in daily living, increased days missed of school, medical consultation for the pain and continued functional impairments into adulthood $41,34,33,18,19,6$. Not only does severe chronic pain result in tremendous suffering, but medical treatment provides only marginal relief. However, the seriousness of chronic non-malignant pain is often not recognized because it doesn't directly affect morbidity or mortality of the patient. The current study underlines the need for clinicians to be alert to suicide ideation and attempt in this at-risk population and to address psychiatric co-morbidities vigilantly.

\section{Acknowledgments}

Financial support: This research was based on data from the Add Health project, a program project designed by J. Richard Udry (principal investigator) and Peter Bearman and funded by grant P01-HD31921 from the National Institute of Child Health and Human Development to the Carolina Population Center, University of North Carolina at Chapel Hill. Additional information on the National Longitudinal Study of Adolescent Health can be obtained at http://www.cpc.unc.edu/projects/addhealth/. Dr van Tilburg received funding for the current study through a seed grant from the UNC Gastrointestinal Biopsychosocial Research Program NIDDK R24 DK067674 (Whitehead/ Drossman). 


\section{Reference List}

1. American Pain Society. Position Statement: Pediatric chronic pain. APS Bulletin. 2001; 11

2. Angst J, Angst F, Stassen HH. Suicide risk in patients with major depressive disorder. J Clin Psychiatry. 1999; 60 (Suppl 2):57-62. [PubMed: 10073389]

3. Apley J, Naish N. Recurrent abdominal pains: a field survey of 1,000 school children. Arch Dis Child. 1958; 33:165-170. [PubMed: 13534750]

4. Archer KJ, Lemeshow S. Goodness-of-fit test for a logistic regression model fitted using survey sample data. The Stata Journal. 2006; 1:97-105.

5. Braden JB, Sullivan MD. Suicidal thoughts and behavior among adults with self-reported pain conditions in the national comorbidity survey replication. J Pain. 2008; 9:1106-1115. [PubMed: 19038772]

6. Campo JV, Di Lorenzo C, Chiappetta L, Bridge J, Colborn K, Gartner JC, Gaffney P, Kocoshis S, Brent D. Adult outcomes of pediatric Recurrent Abdominal Pain: Do they just grow out of it? Pediatrics. 2001; 108:1-7. [PubMed: 11433046]

7. Centers for Disease Control and Prevention. Youth risk behavior surveillance-Unites States, 2009. Morbidity and Mortality Weekly Report. 2010; 59:1-142. [PubMed: 20075837]

8. Cohen, J. Statistical and power analysis for the behavioral sciences. Lawrence Erlbaum Associates; Hillsdale, NJ: 1988.

9. Edwards RR, Smith MT, Kudel I, Haythornthwaite J. Pain-related catastrophizing as a risk factor for suicidal ideation in chronic pain. Pain. 2006; 126:272-279. [PubMed: 16926068]

10. Ernst C, Mechawar N, Turecki G. Suicide neurobiology. Prog Neurobiol. 2009; 89:315-333. [PubMed: 19766697]

11. Goldsmith, SK.; Pellmar, TC.; Kleinman, AM.; Bunney, WE. Reducing suicide: a national imperative. National Academies Press; Washington, DC: 2002.

12. Goodman JE, McGrath PJ. The epidemiology of pain in children and adolescents: a review. Pain. 1991; 46:247-264. [PubMed: 1758709]

13. Greydanus DE, Calles J Jr. Suicide in children and adolescents. Prim Care. 2007; 34:259-273. [PubMed: 17666226]

14. Gureje O. Psychiatric aspects of pain. Curr Opin Psychiatry. 2007; 20:42-46. [PubMed: 17143081]

15. Hallfors DD, Waller MW, Ford CA, Halpern CT, Brodish PH, Iritani B. Adolescent depression and suicide risk: association with sex and drug behavior. Am J Prev Med. 2004; 27:224-231. [PubMed: 15450635]

16. Henningsen P, Zimmermann T, Sattel H. Medically unexplained physical symptoms, anxiety, and depression: a meta-analytic review. Psychosom Med. 2003; 65:528-533. [PubMed: 12883101]

17. Hosmer, DW.; Lemeshow, S. Applied logistic regression. Wiley; New York, NY: 1989.

18. Huguet A, Miro J. The severity of chronic pediatric pain: an epidemiological study. J Pain. 2008; 9:226-236. [PubMed: 18088558]

19. Hunfeld JA, Perquin CW, Duivenvoorden HJ, Hazebroek-Kampschreur AA, Passchier J, van Suijlekom-Smit LW, van der Wouden JC. Chronic pain and its impact on quality of life in adolescents and their families. J Pediatr Psychol. 2001; 26:145-153. [PubMed: 11259516]

20. Hyams JS, Burke G, Davis PM, Rzepski B, Andrulonis PA. Abdominal pain and irritable bowel syndrome in adolescents: a community-based study. J Pediatr. 1996; 129:220-226. [PubMed: 8765619]

21. Merskey, H.; Bogduk, N. IASP Taks Force on Taxonomy: Classification of Chronic Pain. 2. IASP Press; Seattle, WA: 1994.

22. Ilgen MA, Zivin K, McCammon RJ, Valenstein M. Pain and suicidal thoughts, plans and attempts in the United States. Gen Hosp Psychiatry. 2008; 30:521-527. [PubMed: 19061678]

23. Kirkcaldy BD, Siefen GR, Urkin J, Merrick J. Risk factors for suicidal behavior in adolescents. Minerva Pediatr. 2006; 58:443-450. [PubMed: 17008855]

24. Konijnenberg AY, Uiterwaal CS, Kimpen JL, van der HJ, Buitelaar JK, Graeff-Meeder ER. Children with unexplained chronic pain: substantial impairment in everyday life. Arch Dis Child. 2005; 90:680-686. [PubMed: 15899922] 
25. Magni G, Rigatti-Luchini S, Fracca F, Merskey H. Suicidality in chronic abdominal pain: an analysis of the Hispanic Health and Nutrition Examination Survey (HHANES). Pain. 1998; 76:137-144. [PubMed: 9696466]

26. Maletic V, Raison CL. Neurobiology of depression, fibromyalgia and neuropathic pain. Front Biosci. 2009; 14:5291-5338. [PubMed: 19482616]

27. Meier DE, Emmons CA, Litke A, Wallenstein S, Morrison RS. Characteristics of patients requesting and receiving physician-assisted death. Arch Intern Med. 2003; 163:1537-1542. [PubMed: 12860575]

28. Miller V, Hopkins L, Whorwell PJ. Suicidal ideation in patients with irritable bowel syndrome. Clin Gastroenterol Hepatol. 2004; 2:1064-1068. [PubMed: 15625650]

29. Mulvaney S, Lambert EW, Garber J, Walker LS. Trajectories of symptoms and impairment for pediatric patients with functional abdominal pain: a 5-year longitudinal study. J Am Acad Child Adolesc Psychiatry. 2006; 45:737-744. [PubMed: 16721324]

30. O'Carroll PW, Berman AL, Maris RW, Moscicki EK, Tanney BL, Silverman MM. Beyond the Tower of Babel: a nomenclature for suicidology. Suicide Life Threat Behav. 1996; 26:237-252. [PubMed: 8897663]

31. Okuse K. Pain signalling pathways: from cytokines to ion channels. Int J Biochem Cell Biol. 2007; 39:490-496. [PubMed: 17194618]

32. Perquin CW, Hazebroek-Kampschreur AA, Hunfeld JA, Bohnen AM, Suijlekom-Smit LW, Passchier J, van der Wouden JC. Pain in children and adolescents: a common experience. Pain. 2000; 87:51-58. [PubMed: 10863045]

33. Perquin CW, Hazebroek-Kampschreur AA, Hunfeld JA, Suijlekom-Smit LW, Passchier J, van der Wouden JC. Chronic pain among children and adolescents: physician consultation and medication use. Clin J Pain. 2000; 16:229-235. [PubMed: 11014396]

34. Perquin CW, Hunfeld JAM, Hazebroek-Kampschreur AAJM, van Sluijlekom-Smit LWA, Passchier J, Koes BW, van der Wouden JC. Insights in the use of health care services in chronic benign pain in childhood and adolescence. Pain. 2001; 94:205-213. [PubMed: 11690734]

35. Radloff L. The use of the Center for Epidemiological Studies Depression Scale in adolescent and young adults. J Youth Adolesc. 1991; 20:149-166.

36. Radloff LS. The CES-D Scale: A Self-Report Depression Scale for Research in the General Population. Applied Psychological Measurement. 1977; 1:385-401.

37. Ratcliffe GE, Enns MW, Belik SL, Sareen J. Chronic pain conditions and suicidal ideation and suicide attempts: an epidemiologic perspective. Clin J Pain. 2008; 24:204-210. [PubMed: 18287825]

38. Reigstad B, Jorgensen K, Wichstrom L. Pain in adolescent psychiatric patients. Child Adolesc Mental Health. 2006; 11:185-191.

39. Rhee H. Prevalence and predictors of headaches in US adolescents. Headache. 2000; 40:528-538. [PubMed: 10940091]

40. Rhee H, Miles MS, Halpern CT, Holditch-Davis D. Prevalence of recurrent physical symptoms in U. S. adolescents. Pediatr Nurs. 2005; 31:314-9. 350. [PubMed: 16229130]

41. Roth-Isigkeit A, Thyen U, Stoven H, Schwarzenberger J, Schmucker P. Pain among children and adolescents: restrictions in daily living and triggering factors. Pediatrics. 2005; 115:e152-e162. [PubMed: 15687423]

42. Rushton JL, Forcier M, Schectman RM. Epidemiology of depressive symptoms in the National Longitudinal Study of Adolescent Health. J Am Acad Child Adolesc Psychiatry. 2002; 41:199_ 205. [PubMed: 11837410]

43. Saps M, Seshadri R, Sztainberg M, Schaffer G, Marshall BM, Di LC. A Prospective School-based Study of Abdominal Pain and Other Common Somatic Complaints in Children. J Pediatr. 2008

44. Saps M, Sztainberg M, Di LC. A prospective community-based study of gastroenterological symptoms in school-age children. J Pediatr Gastroenterol Nutr. 2006; 43:477-482. [PubMed: 17033522]

45. Smith BH, Hopton JL, Chambers WA. Chronic pain in primary care. Fam Pract. 1999; 16:475482. [PubMed: 10533943] 
46. Smith MT, Edwards RR, Robinson RC, Dworkin RH. Suicidal ideation, plans, and attempts in chronic pain patients: factors associated with increased risk. Pain. 2004; 111:201-208. [PubMed: 15327824]

47. Smith MT, Perlis ML, Haythornthwaite JA. Suicidal ideation in outpatients with chronic musculoskeletal pain: an exploratory study of the role of sleep onset insomnia and pain intensity. Clin J Pain. 2004; 20:111-118. [PubMed: 14770051]

48. Spiegel B, Schoenfeld P, Naliboff B. Systematic review: the prevalence of suicidal behaviour in patients with chronic abdominal pain and irritable bowel syndrome. Aliment Pharmacol Ther. 2007; 26:183-193. [PubMed: 17593064]

49. Steele MM, Doey T. Suicidal behaviour in children and adolescents. part 1: etiology and risk factors. Can J Psychiatry. 2007; 52:21S-33S. [PubMed: 17824350]

50. Stickler GB, Murphy DB. Recurrent abdominal pain. Am J Dis Child. 1979; 133:486-489. [PubMed: 433872]

51. Tang NK, Crane C. Suicidality in chronic pain: a review of the prevalence, risk factors and psychological links. Psychol Med. 2006; 36:575-586. [PubMed: 16420727]

52. Verdu B, Decosterd I, Buclin T, Stiefel F, Berney A. Antidepressants for the treatment of chronic pain. Drugs. 2008; 68:2611-2632. [PubMed: 19093703]

53. Walker LS, Guite JW, Duke M, Barnard JA, Greene JW. Recurrent Abdominal Pain: A potential precursor of Irritable Bowel Syndrome in adolescents and young adults. Journal of Pediatrics. 1998; 132:1010-1015. [PubMed: 9627595]

54. Whitehead WE, Palsson O, Jones KR. Systematic review of the comorbidity of irritable bowel syndrome with other disorders: what are the causes and implications? Gastroenterol. 2002; 122:1140-1156.

55. Woolley SB, Fredman L, Goethe JW, Lincoln AK, Heeren T. Headache complaints and the risk of suicidal thoughts or behaviors. J Nerv Ment Dis. 2008; 196:822-828. [PubMed: 19008733]

56. Youssef NN, Atienza K, Langseder AL, Strauss RS. Chronic abdominal pain and depressive symptoms: analysis of the national longitudinal study of adolescent health. Clin Gastroenterol Hepatol. 2008; 6:329-332. [PubMed: 18258491] 
Table 1

Demographics

\begin{tabular}{|c|c|c|}
\hline & $\mathbf{N}=\mathbf{9 , 9 7 0}$ (Wave I) & $\mathrm{N}=9,925$ (Wave II) \\
\hline Age (Median + range) & $15(11-17)$ & $16(11-18)$ \\
\hline Female & $53.6 \%$ & $53.6 \%$ \\
\hline \multicolumn{3}{|l|}{ Race/ethnicity } \\
\hline Caucasian & $56.0 \%$ & $56.0 \%$ \\
\hline African American & $20.7 \%$ & $20.7 \%$ \\
\hline Hispanic & $15.5 \%$ & $15.4 \%$ \\
\hline \multicolumn{3}{|l|}{ Parent's Education } \\
\hline Less than High School & $12.0 \%$ & $12.0 \%$ \\
\hline High School Graduate & $24.2 \%$ & $24.2 \%$ \\
\hline Some College & $28.5 \%$ & $28.5 \%$ \\
\hline College or higher & $35.3 \%$ & $35.3 \%$ \\
\hline \multicolumn{3}{|l|}{ Suicide } \\
\hline Ideation & $\mathrm{N}=1323(13.3 \%)$ & $\mathrm{N}=1,095(11.0 \%)$ \\
\hline Attempt & $\mathrm{N}=384(3.8 \%)$ & $\mathrm{N}=341(3.4 \%)$ \\
\hline \multicolumn{3}{|l|}{ Weekly Pain } \\
\hline Stomach Ache & $\mathrm{N}=1,797(18.0 \%)$ & $\mathrm{N}=1,653(16.7 \%)$ \\
\hline Headache & $\mathrm{N}=2,949(28.6 \%)$ & $\mathrm{N}=2,687(27.1 \%)$ \\
\hline Muscle/joint Ache & $\mathrm{N}=2,735(27.4 \%)$ & $\mathrm{N}=2,474(24.9 \%)$ \\
\hline \multicolumn{3}{|l|}{ Pain at both Wave I and II } \\
\hline Stomach Ache & \multicolumn{2}{|c|}{$39.8 \%$} \\
\hline Headache & \multicolumn{2}{|c|}{$55.9 \%$} \\
\hline Muscle/joint ache & \multicolumn{2}{|c|}{$46.7 \%$} \\
\hline
\end{tabular}


Table 2

Association between pain and suicide ideation/attempt in the last year while controlling for age and gender

\begin{tabular}{|c|c|c|c|c|}
\hline & \multicolumn{4}{|c|}{ Wave I } \\
\hline & \multicolumn{2}{|c|}{$\begin{array}{c}\text { Suicide ideation Odds Ratio (95\% confidence } \\
\text { interval) }\end{array}$} & \multicolumn{2}{|c|}{$\begin{array}{c}\text { Suicide attempt Odds Ratio (95\% confidence } \\
\text { interval) }\end{array}$} \\
\hline \multicolumn{5}{|l|}{ Wave I } \\
\hline Depression & Not entered in model & $1.1(1.1-1.1)$ & Not entered in model & $1.1(1.1-1.1)$ \\
\hline Headache & $1.5(1.3-1.8)$ & $1.3(1.1-1.5)$ & $1.4(1.1-1.9)$ & $1.2(.9-1.6)$ \\
\hline Stomachache & $1.6(1.3-1.9)$ & $1.0(.8-1.2)$ & $1.8(1.3-2.4)$ & $1.1(.8-1.6)$ \\
\hline Muscle/joint ache & $1.5(1.2-1.7)$ & $1.3(1.1-1.5)$ & $1.3(.99-1.8)$ & $1.1(.8-1.5)$ \\
\hline \multirow[t]{3}{*}{ Goodness of Fit ${ }^{\#}$} & $\mathrm{~F}_{\mathrm{adj}}=.28 ; \mathrm{p}=.98$ & $\mathrm{~F}_{\mathrm{adj}}=.1 .11 ; \mathrm{p}=.36$ & $\mathrm{~F}_{\mathrm{adj}}=.59 ; \mathrm{P}=.80$ & $\mathrm{~F}_{\mathrm{adj}}=3.4 ; \mathrm{p}=.001$ \\
\hline & \multicolumn{4}{|c|}{ Wave II } \\
\hline & \multicolumn{2}{|c|}{$\begin{array}{c}\text { Suicide ideation Wave II Odds Ratios (95\% } \\
\text { Confidence Interval) }\end{array}$} & \multicolumn{2}{|c|}{$\begin{array}{l}\text { Suicide attempt Wave II Odds Ratios (95\% } \\
\text { Confidence Interval) }\end{array}$} \\
\hline \multicolumn{5}{|l|}{ Wave II } \\
\hline Depression & Not entered in model & $1.1(1.1-1.1)$ & Not entered in model & $1.1(1.1-1.1)$ \\
\hline Headache & $1.7(1.4-2.0)$ & $1.4(1.2-1.7)$ & $2.1(1.6-2.8)$ & $1.6(1.2-2.2)$ \\
\hline Stomachache & $1.9(1.6-2.3)$ & $1.4(1.2-1.7)$ & $1.8(1.3-2.4)$ & $1.3(.9-1.8)$ \\
\hline Muscle/joint ache & $1.4(1.2-1.7)$ & $1.2(.91-1.5)$ & $1.5(1.1-2.1)$ & $1.1(.8-.92)$ \\
\hline Goodness of fit $\#$ & $\mathrm{~F}_{\mathrm{adj}}=1.2 ; \mathrm{p}=.29$ & $\mathrm{~F}_{\mathrm{adj}}=.93 ; \mathrm{p}=.50$ & $\mathrm{~F}_{\mathrm{adj}}=2.0 ; \mathrm{p}=.46$ & $\mathrm{~F}_{\mathrm{adj}}=1.2 ; \mathrm{p}=.29$ \\
\hline
\end{tabular}

* Odds ratios are considered to be statistically significant if the $95 \%$ confidence interval does not overlap with 1.0 .

${ }^{\#}$ Goodness of fit statistic is considered to show a good fit for the model if $\mathrm{p}>0.05$ 

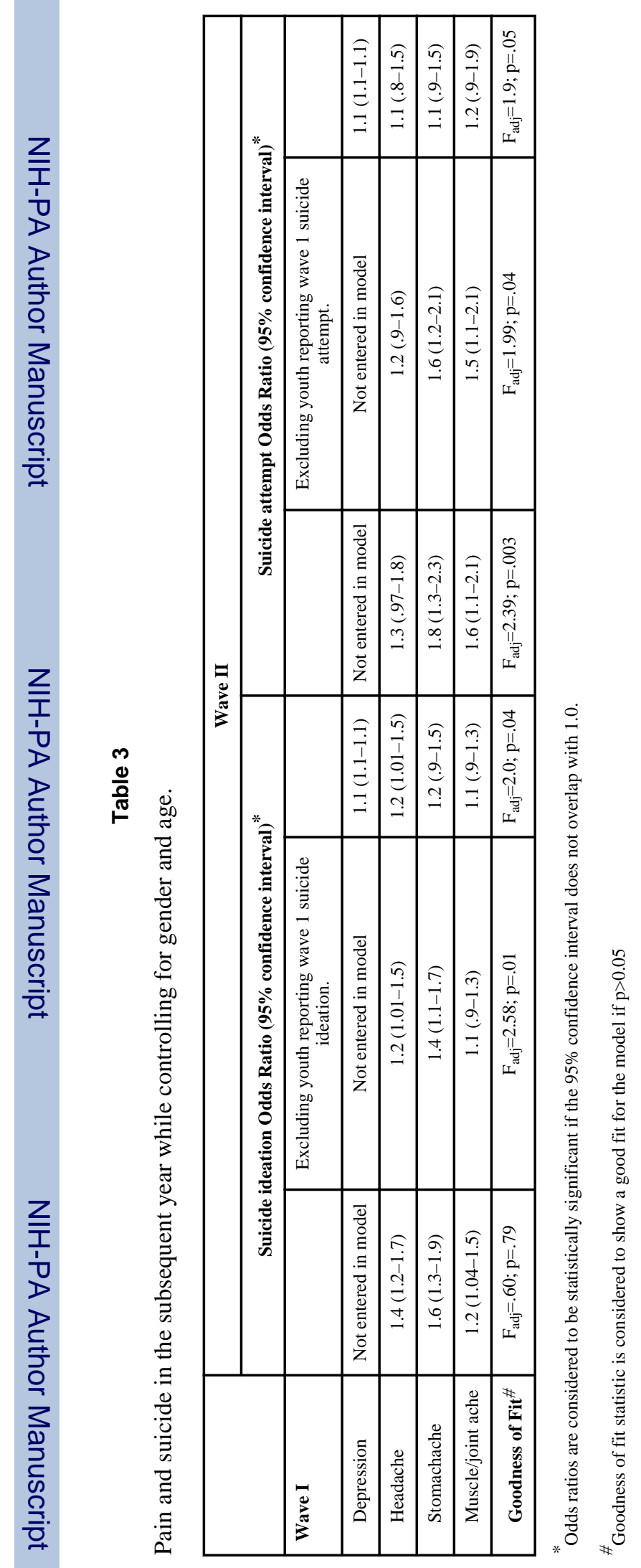

J Pain. Author manuscript; available in PMC 2012 October 1. 